\section{TDAH ao longo da vida}

Mario Rodrigues Louzã Neto et al., Editora Artmed; 2009. 388p.

O transtorno de déficit de atenção/hiperatividade (TDAH) possui uma longa e polêmica história dentro da psiquiatria. Inicialmente restrito à infância, gradualmente, durante a segunda metade do século passado, foi reconhecido também em adultos. Está associado a múltiplos prejuízos em seus portadores, quer em atividades acadêmicas, quer em relacionamentos e, posteriormente, na vida profissional. Sendo assim, apresenta grandes desafios para diversos tipos de profissionais que lidam com estes indivíduos nas escolas e consultórios. Complicando a situação, é regra a presença de inúmeras comorbidades que adicionam complexidade ao que já não era simples.

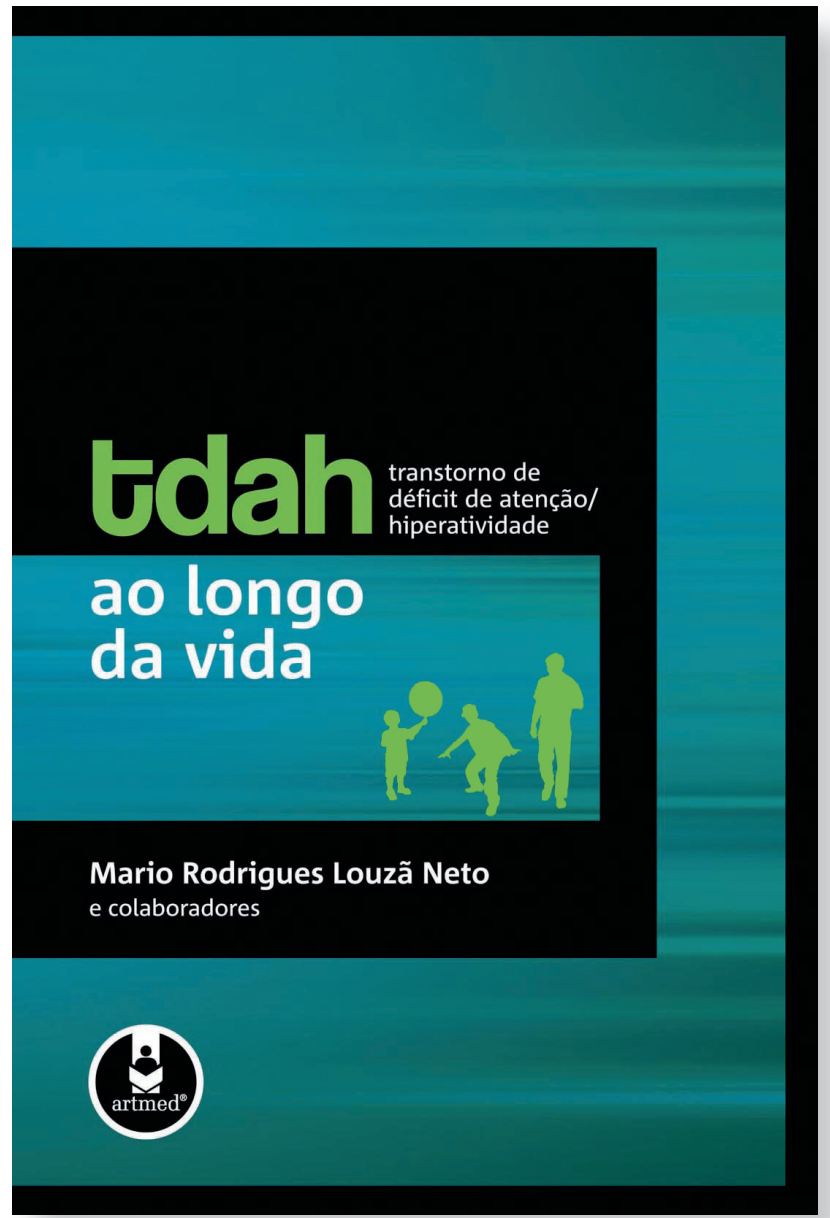

Dentro deste cenário, é muito bem-vinda a recente publicação de Louzã Neto et al.: TDAH ao longo da vida. É, talvez, o primeiro livro em língua portuguesa a contemplar este transtorno com uma visada ao mesmo tempo integradora e esclarecedora, condizente com a atual maneira de conceber o TDAH como um transtorno neurodesenvolvimental, que altera suas características ao longo do ciclo vital. Comumente, o TDAH em adultos seria abordado como um capítulo em um livro de um transtorno infantil. Pois Louzã Neto et al. inovam ao colocar capítulos de adultos e crianças lado a lado em descrição clínica, comorbidades, diagnóstico diferencial e tratamento. Ao mesmo tempo em que estende a concepção de um transtorno infantil para outro possível também em adultos, com as diversas especificidades próprias a esta fase da vida, o livro convoca um time abrangente de especialistas verdadeiramente multidisciplinar. Como camadas geológicas de um mesmo terreno, pesquisadores relacionados aos diversos grupos acadêmicos brasileiros que investigam o TDAH - de geneticistas a psicanalistas - contribuíram no esforço de tornar rico e plural o detalhamento desse transtorno. Estes múltiplos olhares garantiram abrangência e profundidade. São raros capítulos em livros desta natureza que abordem, por exemplo, psicodinâmica, qualidade de vida ou transtornos do sono. Pois é possível encontrá-los aqui.

O formato quase "pocket", de fácil manuseio, torna acessível a consulta. Os capítulos estão bem dimensionados e o livro, como um todo, é de leitura agradável e objetiva. Representa excelente introdução para um amplo leque de profissionais que queiram conhecer melhor o TDAH, desde pedagogos até clínicos que atendam estes pacientes em seus consultórios. Certamente, será também útil em dúvidas frequentes mesmo para especialistas na área, como indicações de tratamentos ou dificuldades diagnósticas na presença de comorbidades. Sendo assim, preenche com qualidade nossas bibliotecas.

Marcelo Victor

Programa de Pós-Graduação em Psiquiatria, Faculdade de Medicina, Universidade Federal do Rio Grande do Sul (UFRGS), Porto Alegre (RS), Brasil

Pesquisador do Programa de TDAH em Adultos, Hospital de Clínicas de Porto Alegre (PRODAH), Porto Alegre (RS), Brasil 